\title{
Design of G-Shaped Defected Ground Structure for Bandwidth Enhancement
}

\author{
Gurpreet Singh \\ Research Scholar (M.Tech) \\ SBSSTC, Ferozepur
}

\author{
Rajni \\ Assoc. Prof. \\ SBSSTC, Ferozepur
}

\author{
Anupma Marwaha \\ Assoc. Prof. \\ SLIET, Longowal
}

\begin{abstract}
This paper describes the effect of incorporation of G-shaped defected ground structure (DGS) on the performance of the simple microstrip patch antenna (MPA). The various antenna parameters such as Bandwidth (B.W.), Return loss $\left(\mathrm{S}_{11}\right)$ and Voltage Standing Wave Ratio (VSWR) get much improved in proposed antenna with Defected Ground Structure. Comparison of the performance characteristics of the proposed antenna with simple MPA without defect has been presented by simulating the antennas with Finite Element Machine (FEM) based software High Frequency Structure Simulator (HFSS) software Version-13.0 package. Simulated results reveal that the bandwidth of MPA is increased by $598.4 \mathrm{MHz}$ with very good return loss of $-49.43 \mathrm{~dB}$ with Gshaped DGS. Proposed antenna finds its application in C-band such as in satellite communications, Wi-Fi etc.
\end{abstract}

\section{General Terms}

Bandwidth (B.W.), return loss $\left(\mathrm{S}_{11}\right)$, Voltage Standing Wave Ratio (VSWR), gain and directivity.

\section{Keywords}

Defected Ground Structure (DGS), Microstrip Patch Antenna (MPA).

\section{INTRODUCTION}

Microstrip antenna is a topic of intensive research in recent years with the explosive growth of wireless system and booming demand for a variety of new wireless application. In recent years, as the demand of the small systems have increased, small size antennas have drawn much interest of researchers [1].

Microstrip antenna technology fulfill the requirements of modern communication system such as low profile, light weight, easy to fabrication, and conformability to mounting hosts in addition size reduction and bandwidth [1]. Therefore, the selection of microstrip antenna is suitable to apply at various fields such as telecommunication, medical application, satellite and military system [2]. However, microstrip antenna has its inherent shortcomings such as narrow bandwidth and low gain. The microstrip patch is inherently a narrow-band structure and a larger thickness of the grounded substrate helps in increasing its bandwidth [3]. But limited ground plane size is an essential requirement for its compactness as well as compatibility with the mobile wireless equipments. However, the bandwidth and the size of an antenna are generally conflicting properties i.e. improvement of one of the characteristics normally results in degradation of the other.
To overcome these drawbacks and to improve antenna characteristics, different techniques have been used by the researchers such as slotting, DGS, use of dielectric substrate of high permittivity [4] etc. The other method to miniaturize the microstrip antenna is to modify its geometry using irises [5] or folded structures [6-7] based on the perturbation effect [8]. Defected ground structure (DGS), where the ground plane metal of the microstrip antenna design is modified intentionally in order to enhance the performance [9-11]. The name for this technique simply means that a "Defect" has been etched off in the ground plane, which disturbs the shield current distribution in the ground plane and influences the input impedance as well as current flow of the antenna. A defect in the ground plane causes to increase in effective capacitance and inductance.

DGS may have various shaped slot like U-shaped slot, Eshaped slot, L-shaped slot, I-shaped slot etc. which helps to improve resonant bandwidth. Different types of antennas works in different frequency bands such as L-band ranges between $1-2 \mathrm{GHz}$, S-band ranges between $2-4 \mathrm{GHz}, \mathrm{C}$-band ranges between $4-8 \mathrm{GHz}$ and $\mathrm{X}$-band ranges between 8-12 $\mathrm{GHz}$ etc. Each of these frequency bands has different working applications. Similarly proposed antenna finds its application in C-band such as in satellite communications, Wi-Fi etc. In this paper work, the design incorporates G-Shaped Defected Ground Structure in ground plane, which disturbs shielded current distribution in ground plane [12-13].

\section{ANTENNA DESIGN}

The equivalent circuit for a DGS is a parallel- tuned circuit in series with the transmission line to which it is coupled [14] as shown in Fig. 1. The input and output impedances are that of transmission line section, while the equivalent values of L, C and $\mathrm{R}$ are determined by the dimensions of the DGS structure and its position relative to the transmission line.

By specifying the following conditions, an antenna can be easily trimmed to the desired center frequency:

$$
f_{10}=\frac{c}{\sqrt{\varepsilon_{r}}}\left(\frac{1}{2 L}\right)
$$

where, $f_{10}$ is resonant frequency in case of rectangular patch, "L" is length of patch, $\varepsilon_{r}$ is substrate's relative permittivity.

This is equivalent to say that the length " $L$ " is one-half of a wavelength in the dielectric:

$$
L=\frac{\lambda_{d}}{2}=\frac{\frac{\lambda_{0}}{2}}{\sqrt{\varepsilon_{r}}}
$$

where, $\lambda_{d}$ is the wavelength in dielectric material. 


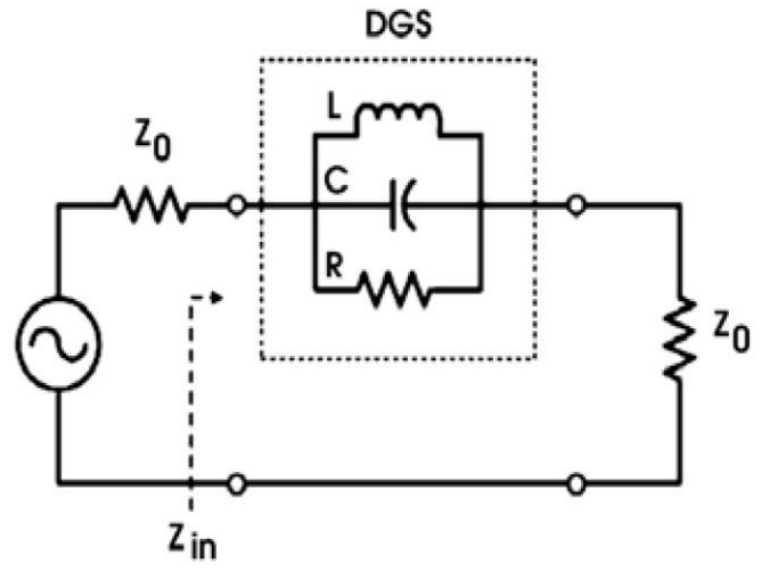

Fig 1: Equivalent circuit of a DGS element

Both MPA and proposed antennas are designed on Rogers RT/Duroid $5880(\mathrm{tm})$ substrate with thickness $\left(\mathrm{h}_{\mathrm{s}}\right)$ of 0.794 $\mathrm{mm}$ having relative permittivity $\left(\varepsilon_{\mathrm{r}}\right)$ of 2.2 . The patch has the dimensions of $12.45 \mathrm{~mm} \times 16 \mathrm{~mm}$ with height $\left(\mathrm{h}_{\mathrm{p}}\right)$ of $0.05 \mathrm{~mm}$. The ground has the dimensions of $28.1 \mathrm{~mm} \times 32 \mathrm{~mm}$ with height $\left(\mathrm{h}_{\mathrm{g}}\right)$ of $0.05 \mathrm{~mm}$. Antenna is excited with microstrip feed having characteristics impedance of $50 \Omega$. The feed has dimension of $8 \mathrm{~mm} \times 2.46 \mathrm{~mm}$ with height $\left(\mathrm{h}_{\mathrm{f}}\right)$ of $0.05 \mathrm{~mm}$. The complete geometry of simple MPA is shown in Fig. 2.

The proposed antenna design for C-band incorporates a GShaped slot in Ground. In G-shaped DGS antenna, the distance between inner turns is kept $9 \mathrm{~mm}$ and the width of turn is $2 \mathrm{~mm}$. The complete geometry of proposed G-shaped DGS antenna is shown in Fig. 3.

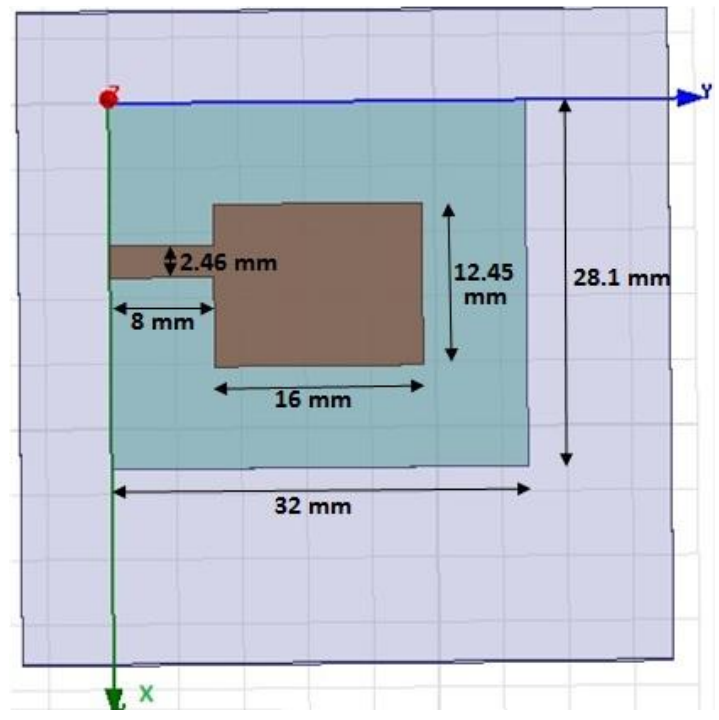

Fig 2: Geometry of simple MPA antenna

G-shaped DGS antenna also gives a large bandwidth as compared to simple MPA. To acquire large bandwidth, an antenna must satisfy the following relation:

$$
\begin{aligned}
& W<2 L \\
& W=1.5 L \text { (Typical value) }
\end{aligned}
$$

where, "L" represents the length of patch. The width "W" is usually chosen to be larger than L (to get higher bandwidth).

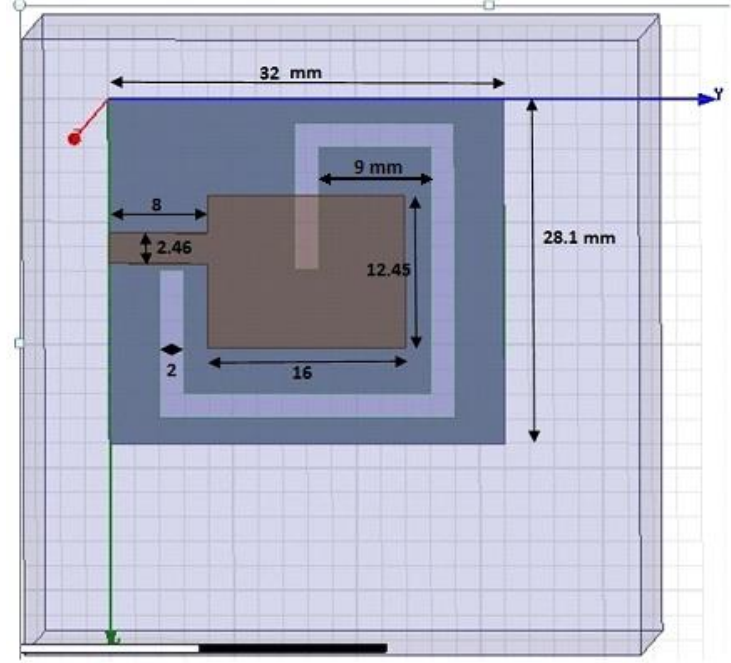

Fig 3: Geometry of G-shaped DGS antenna

Bandwidth is related to substrate thickness $\left(\mathrm{h}_{\mathrm{s}}\right)$ and substrate permittivity $\left(\varepsilon_{r}\right)$. If ' $h_{\mathrm{s}}$ ' is greater than $0.05 \lambda_{0}$, then probe inductance becomes too large to match the impedance. A higher substrate permittivity allows for a smaller antenna but lower bandwidth. Thus bandwidth and size of an antenna are generally conflicting properties i.e. improvement of one of the characteristics normally results in degradation of the other. In this paper, an appropriate dielectric material "Rogers RT/Duroid $5880 \mathrm{tm}$ " is used for substrate with thickness $\left(\mathrm{h}_{\mathrm{s}}\right)$ of $0.794 \mathrm{~mm}$ having relative permittivity $\left(\varepsilon_{\mathrm{r}}\right)$ of 2.2 and also satisfies all the above mentioned conditions.

In the design of patch, a few equations are used as reference before optimizing the dimension. With a specific resonant frequency $f_{r}$, the width and the length of patch are expressed as follows [15];

$$
\begin{aligned}
& \mathrm{W}_{\mathrm{P}}=\frac{1}{2 \mathrm{f}_{\mathrm{r}} \sqrt{\mu_{0 \varepsilon_{0}}}} \sqrt{\frac{2}{\varepsilon_{r}+1}} \\
& \mathrm{~L}_{\mathrm{P}}=\mathrm{L}_{\mathrm{e}}-\Delta \mathrm{L} \\
& \mathrm{L}_{\mathrm{e}}=\frac{c}{2 f_{0 \sqrt{\varepsilon_{e}}}} \\
& \Delta \mathrm{L}=0.412 \mathrm{~h} \frac{\left(\varepsilon_{e}+0.3\right)\left(\frac{W}{h}+0.2664\right)}{\left(\varepsilon_{e}-0.258\right)\left(\frac{W}{h}+0.8\right)} \\
& \varepsilon_{e}=\frac{\varepsilon_{r}+1}{2}+\frac{\varepsilon_{r}-1}{2}\left[1+12 \frac{h}{W}\right]^{\frac{-1}{2}}
\end{aligned}
$$

where, $\quad \mathrm{W}_{\mathrm{P}}=$ width of patch

$\mathrm{LP}=$ length of patch

$\Delta \mathrm{L}=$ extended length of patch

$\mathrm{L}_{\mathrm{e}}=$ effective length of patch

$\varepsilon_{\mathrm{e}}=$ effective dielectric constant substrate

$\varepsilon_{\mathrm{r}}=$ relative dielectric constant of substrate

Table 1 shows some common design specifications for both antennas i.e. DGS and simple MPA. 
Table 1. Common Design Specifications for simple MPA and DGS Antennas

\begin{tabular}{|l|c|c|}
\hline $\begin{array}{l}\text { Sr. } \\
\text { No. }\end{array}$ & Specifications & $\begin{array}{c}\text { Dimensions } \\
(\mathbf{m m}) / \text { Values }\end{array}$ \\
\hline 1. & Ground $\left(\mathrm{L}_{\mathrm{g}} \times \mathrm{W}_{\mathrm{g}} \times \mathrm{h}_{\mathrm{g}}\right)$ & $28.1 \times 32 \times 0.05$ \\
\hline 2. & Substrate $\left(\mathrm{L}_{\mathrm{s}} \times \mathrm{W}_{\mathrm{s}} \times \mathrm{h}_{\mathrm{s}}\right)$ & $28.1 \times 32 \times 0.79$ \\
\hline 3. & Patch $\left(\mathrm{L}_{\mathrm{P}} \times \mathrm{W}_{\mathrm{P}} \times \mathrm{h}_{\mathrm{p}}\right)$ & $12.45 \times 16 \times 0.05$ \\
\hline 4. & Feed $\left(\mathrm{L}_{\mathrm{f}} \times \mathrm{W}_{\mathrm{f}} \times \mathrm{h}_{\mathrm{f}}\right)$ & $2.46 \times 8 \times 0.05$ \\
\hline 5. & $\begin{array}{c}\text { Permittivity of substrate } \\
\text { material "Rogers } \\
\text { RT/Duroid } 5880 \text { tm" }\left(\varepsilon_{r}\right)\end{array}$ & \\
\hline
\end{tabular}

\section{RESULTS AND DISCUSSIONS}

The performance parameters of both antennas i.e. simple MPA and G-shaped DGS antenna are simulated with High Frequency Structure Simulator (HFSS) software Version13.0.

\subsection{Return loss $\left(\mathrm{S}_{11}\right)$ and bandwidth}

$S_{11}$ represents how much power is reflected from the antenna, and hence is known as the reflection coefficient. The bandwidth of the antenna can be calculated from return loss versus frequency plot at $-10 \mathrm{~dB}$.

Fig. 4 shows that when defect in ground plane is introduced, the proposed antenna resonate in $\mathrm{C}$-band at resonant frequency $\left(f_{r}\right)=4.7154 \mathrm{GHz}$. A very good return loss of $49.43 \mathrm{~dB}$ at this resonating frequency $\left(\mathrm{f}_{\mathrm{r}}\right)$ is obtained for this structure. At this resonant frequency, it gives a maximum impedance bandwidth of $687.5 \mathrm{MHz}$ (i.e. $\mathrm{m}_{1}-\mathrm{m}_{2}$ ).

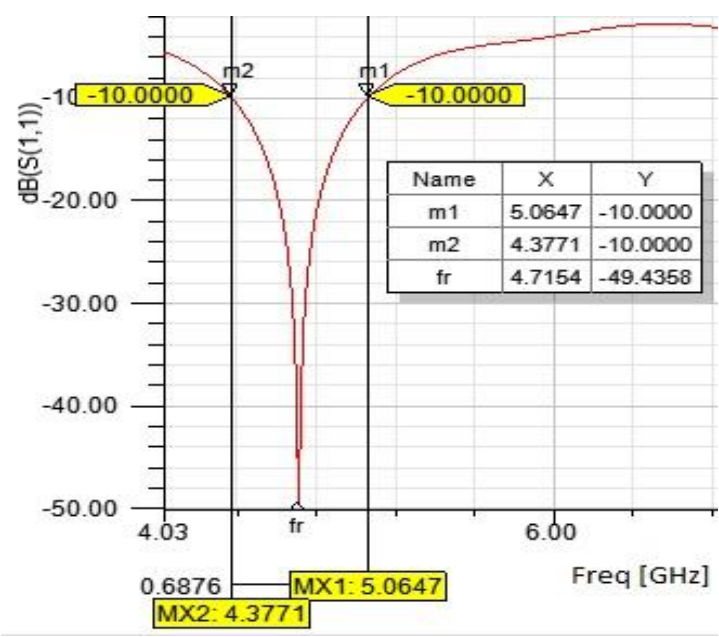

Fig 4: Return loss $\left(S_{11}\right)$ of G-shaped DGS antenna

While from the Fig. 5, it is evident that in case of antenna structure without slotting in ground, the antenna also resonates in the C-band but at resonant frequency $f_{r}=7.53$ $\mathrm{GHz}$. The bandwidth of the microstrip patch antenna without slotting is $89.1 \mathrm{MHz}$ at $\mathrm{f}_{\mathrm{r}} 7.5351 \mathrm{GHz}$ and also results in poor return losses $\left(\mathrm{S}_{11}\right)$ of $-11.78 \mathrm{~dB}$.

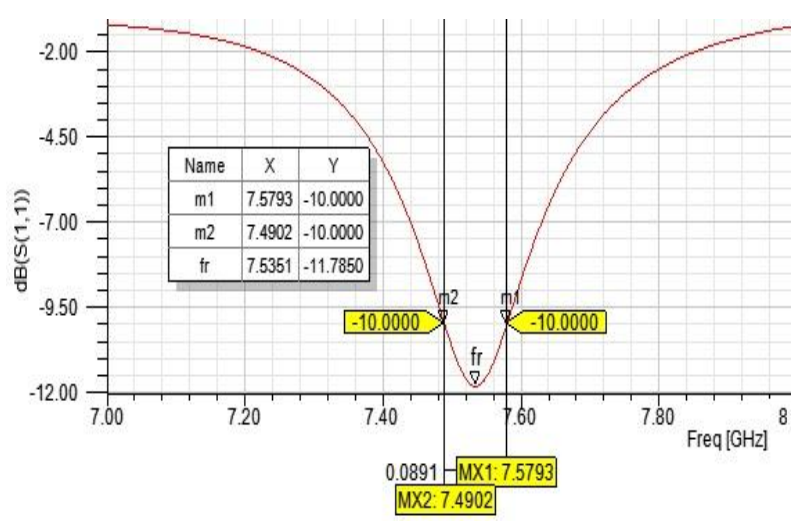

Fig 5: Return loss $\left(S_{11}\right)$ of simple MPA without slotting

Thus it is concluded that with G-Shaped DGS, the bandwidth gets increased by $598.4 \mathrm{MHz}$ than simple MPA (i.e. 687.5 $\mathrm{MHz}-89.1 \mathrm{MHz}=598.4 \mathrm{MHz}$ ).

\subsection{Voltage Standing Wave Ratio (VSWR)}

VSWR is a measure of how well matched antenna is to the cable impedance. A perfectly matched antenna would have a VSWR of 1:1. This indicates how much power is reflected back or transferred into a cable. VSWR obtained from the simulation of G-type DGS antenna is $1.006 \mathrm{~dB}$ which is approximately equals to $1: 1$ as shown in Fig. 6. This shows the perfectly matching of an antenna with the port.

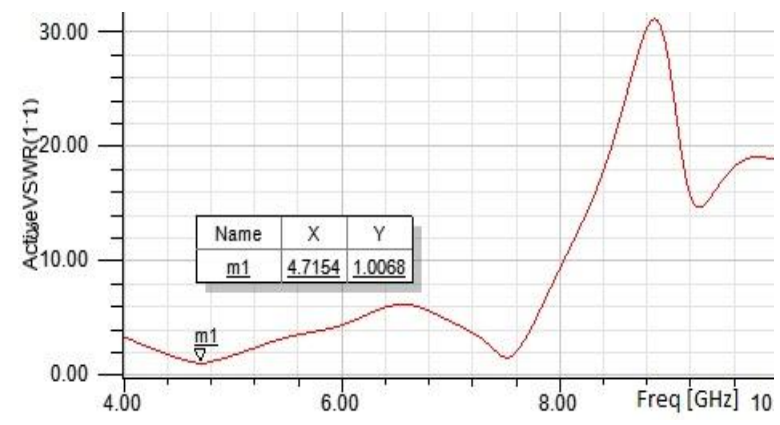

Fig 6: VSWR Plot of G-Shaped DGS Antenna

While the VSWR at resonating frequency $\mathrm{f}_{\mathrm{r}}=7.53 \mathrm{GHz}$, in case of simple MPA is 1.6935 as shown in Fig. 7. As the value of VSWR is more than 1.5 , the port is poorly matched.

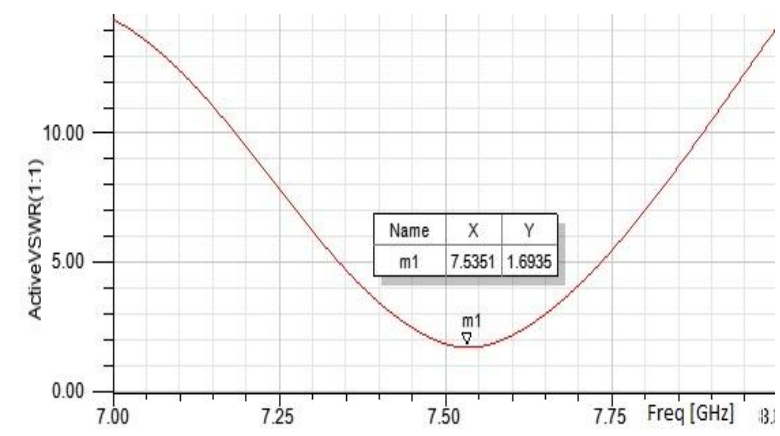

Fig 7: VSWR Plot of simple MPA without slotting 


\subsection{Input Impedance $\left(Z_{\text {in }}\right)$}

For an efficient transfer of energy, the impedance of the antenna and of feed line connecting them must be the same. Transceivers and their transmission lines are typically designed for $50 \Omega$ impedance. Fig. 8 shows that the input impedance of G-shaped DGS antenna at the center frequency $4.71 \mathrm{GHz}$ is $49.78 \Omega$; this is very close to the expected $50 \Omega$.

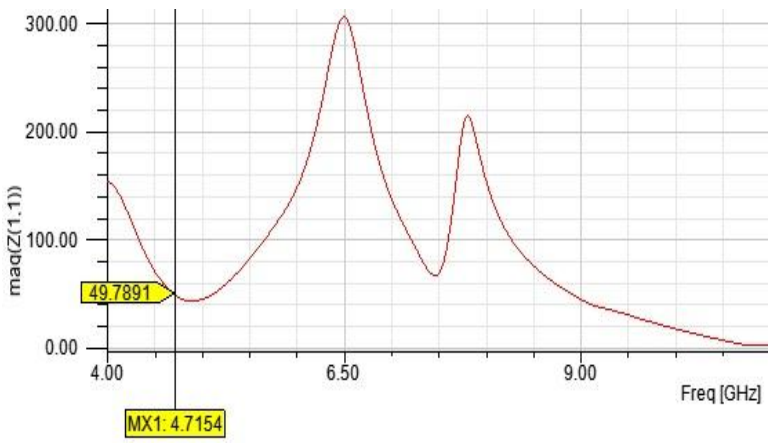

Fig 8: Input Impedance $\left(\mathrm{Z}_{\text {in }}\right)$

\subsection{Total gain}

Gain of an antenna is the ratio of the maximum radiation intensity in a particular direction from the test antenna to the maximum radiation intensity from reference antenna, when same input power is applied to both antennas.

Fig. 9 shows the simulated Polar plot for gain, obtained from G-shaped DGS Antenna. The Total Gain provided by proposed antenna is $7.12 \mathrm{~dB}$.
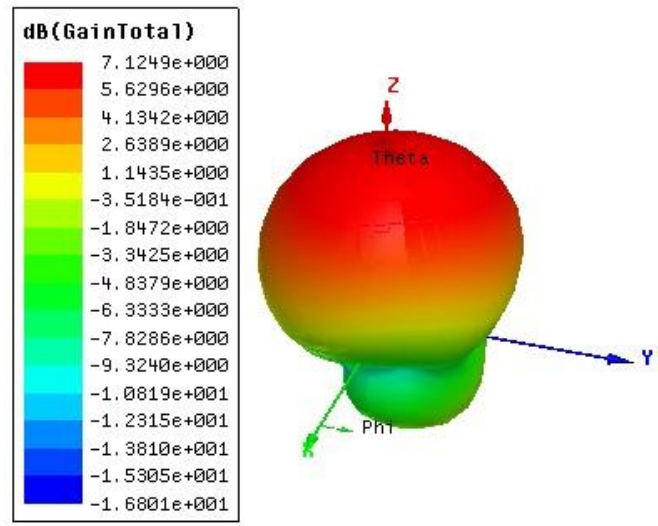

Fig 9: 3D Polar Plot of G-shaped DGS antenna for total gain

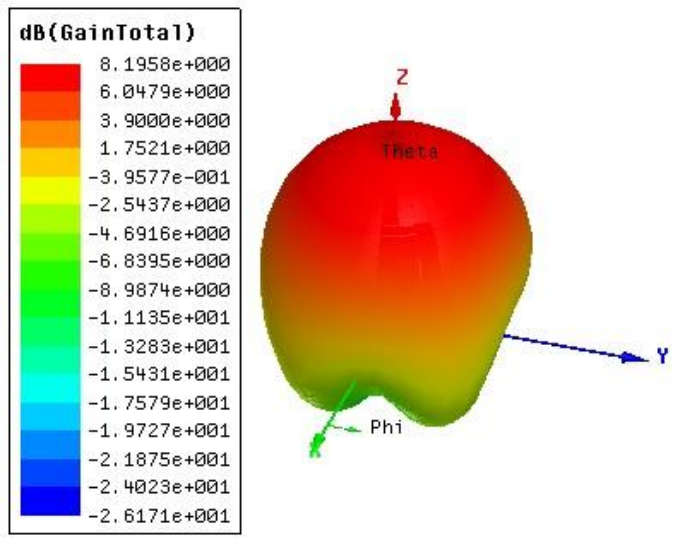

Fig 10: 3D polar plot of simple MPA antenna for total gain

While the simulated gain at resonant frequency $\mathrm{f}_{\mathrm{r}}=7.53 \mathrm{GHz}$, in case of simple MPA is $8.19 \mathrm{~dB}$ as shown in Fig. 10.

\subsection{Directivity}

Directivity of a non-isotropic antenna is equal to the ratio of its radiation intensity in a given direction over that of an isotropic antenna.

Fig. 11 shows the 3D Polar Plot of Total Directivity obtained from G-slot DGS Antenna. This figure shows that the Total Directivity of the proposed antenna is $7.14 \mathrm{~dB}$.

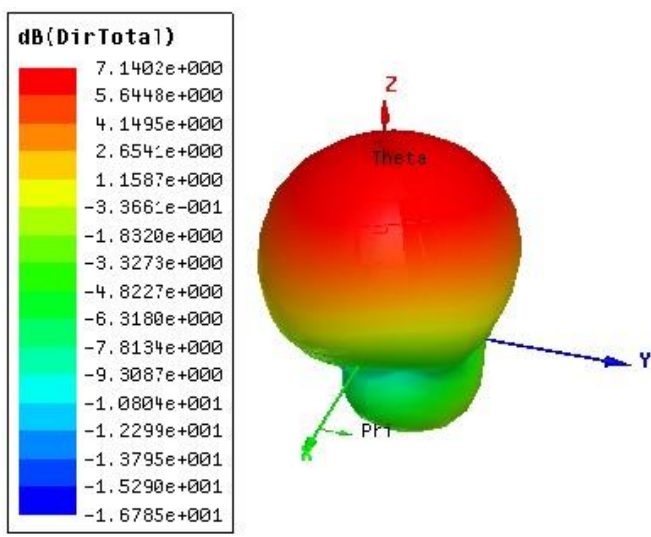

Fig 11: 3D Polar plot of G-shaped DGS antenna for total directivity

While the simulated directivity at resonant frequency $\mathrm{f}_{\mathrm{r}}=7.53$ $\mathrm{GHz}$, in case of simple MPA antenna is $8.20 \mathrm{~dB}$ as shown in Fig. 12. 


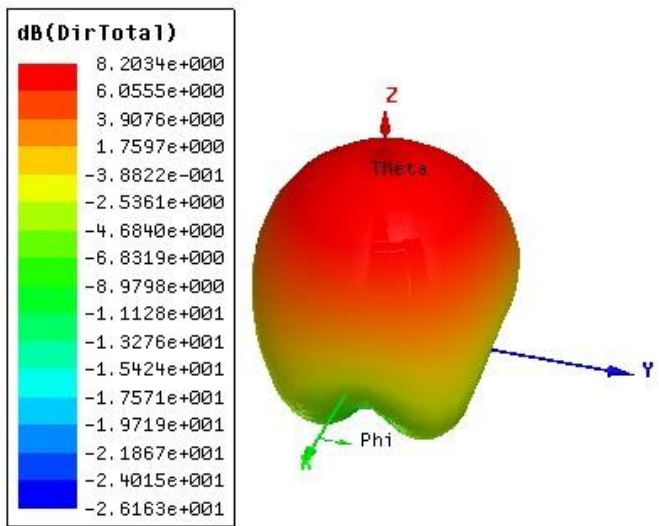

Fig 12: 3D polar plot of simple MPA for total directivity

Table 2 summarizes the obtained simulation features of the designed antennas.

Table 2. Comparison of simulated results of both antennas

\begin{tabular}{|l|l|c|c|}
\hline $\begin{array}{l}\text { Sr. } \\
\text { No. }\end{array}$ & \multicolumn{1}{|c|}{ Parameters } & $\begin{array}{c}\text { MPA } \\
\text { Antenna }\end{array}$ & $\begin{array}{c}\text { G-Shaped } \\
\text { DGS Antenna }\end{array}$ \\
\hline 1. & $\begin{array}{l}\text { Resonating } \\
\text { Frequency }(\mathrm{GHz})\end{array}$ & 7.53 & 4.71 \\
\hline 2. & Bandwidth (MHz) & 89.1 & 687.5 \\
\hline 3. & Return Loss (dB) & -11.78 & -49.43 \\
\hline 4. & VSWR & 1.69 & $1.006(\approx 1)$ \\
\hline
\end{tabular}

\section{CONCLUSION}

Simple MPA gives bandwidth of $89.1 \mathrm{MHz}$ at resonant frequency of $7.53 \mathrm{GHz}$ and also results in poor return loss of $11.78 \mathrm{~dB}$ as shown in Fig. 5. While G-Shaped DGS antenna provides bandwidth of $687.5 \mathrm{MHz}$ and return loss reaches up to $-49.43 \mathrm{~dB}$ at resonating frequency $\left(\mathrm{f}_{\mathrm{r}}\right)$ of $4.71 \mathrm{GHz}$ as shown in Fig. 4. It has been observed from the results that the impedance bandwidth of G-Shaped DGS antenna is very large as compared to the simple MPA. Bandwidth is increased by 598.4 MHz with G-shaped DGS antenna than simple MPA. The obtained value of VSWR is $1.006 \mathrm{~dB}$ in case of proposed G-shaped DGS antenna i.e. equal to unity. This G-Shaped DGS antenna design is useful for Wi-Fi and satellite communications.

\section{REFERENCES}

[1] A.K. Skrivernilk, Zurcher O. Staub and J.R. Mosig, "PCS antenna design: The challenge of miniatururization" IEEE Antenna Propagation Magazine, 43 (4), pp 12-27, August 2011M. Young, The Techincal Writers Handbook. Mill Valley, CA: University Science, 1989.
[2] S. Indrasen and T. V.S., "Micro strip Patch Antenna and its Applications: a Survey," International Journal of Computer Technology Application, vol. II, pp. 15951599,2011

[3] M. T. Islam, M. N. Shakib, N. Misran and T. S. Sun, "Broadband Microstrip Patch Antenna," European Journal of Scientific Research, vol. 27, no. 2, pp. 174$180,2009$.

[4] T.K. Lo and Y.Hwang, "Microstrip antannas of very high permittivity for personal communications",1997 Asia Pacific Microwave Conference, pp. 253-256.

[5] J.S. Seo and J.M. Woo, "Miniaturizaation of microstrip antenna using iris," Electron Lett., vol.40 no. 12, pp.718719,Jun.2004

[6] K.L.Wong, Compact and Broadband Microstrip antennas. New York: Wiley-Interscience,2002, p.5.

[7] H. M. Heo and J. M. Woo, "Miniaturization of microstrip antenna using folded structure," in Proc. Int. Symp. Antennas Propag., endai,Japan, Aug. 2004, pp. 985-988.

[8] R. F. Harrington, Time-Harmonic Electromagnetic Fields. Piscataway, NJ: IEEE Press, 2001.

[9] Naftali Herscovici, "A Wide-Band Single Layer Patch Antenna", IEEE Transactions on Antennas and Propagation, 46, (4), pp. 471-474, 1998.

[10] L.T.Wang, and J.S. Sun, "The compact broadband microstrip antenna with defective ground plane," IEE International Conference on Antenna and Propagation, Vol. 2, 622-624, Apr. 2003.

[11] H. Liu, Z. Li, and X. Sun, "Compact defected ground structure in microstrip technology," Electron. Lett., Vol. 41, No. 3, pp.132-134, 2005.

[12] Arya, A.K. Kartikeyan, M.V., Patnaik, A., "Efficiency enhancement of microstrip patch antennas with Defected Ground Structure," IEEE proc. Recent Advanced in Microwave theory and applications (MICROWAVE-08), pp.729-731 November 2008.

[13] F. Y. Zulkifli, E. T. Rahardjo, and D. Hartanto, " Mutual Coupling Reduction using Dumbbell Defected Ground Structure for Multiband Microstrip antenna array" Progress In Electromagnetics Research Letters, Vol. 13, 29-40, 201.

[14] Islam, F., Ali, M., Majlis, B., and Misran, N. (2008). Design, simulation and fabrication of a microstrip patch antenna for dual band application. IEEE, 59:799-802.

[15] B. C.A., Antenna Theory: Analysis and Design, 3rd edition ed.,Hoboken, New Jersey.: A John Wiley \& Sons, INC., 2005. 